\title{
Effect of Sodium Silicate and Salicylic Acid on Sodium and Potassium Ratio in Wheat (Triticum aestivum $L$.) Grown Under Salt Stress
}

Ayesha Mushtaq ( $\sim$ ayeshamushtaq2000@yahoo.com)

Sardar Bahadur Khan Women's University https://orcid.org/0000-0002-2010-2130

Nazish Sabir

Sardar Bahadur Khan Women's University

Tasneem Kousar

Sardar Bahadur Khan Women's University

Sabeena Rizwan

Sardar Bahadur Khan Women's University

Uzma Jabeen

Sardar Bahadur Khan Women's University

Farrukh Bashir

Sardar Bahadur Khan Women's University

Sadia Sabir

COMSATS University Islamabad

Naeem Shahwani

BUITEMS: Balochistan University of Information Technology and Management Sciences

\section{Research Article}

Keywords: Potassium, Sodium silicate, Salicylic acid, Salinity, Sodicity

Posted Date: July 14th, 2021

DOI: https://doi.org/10.21203/rs.3.rs-680832/v1

License: (c) (1) This work is licensed under a Creative Commons Attribution 4.0 International License. Read Full License 


\section{Abstract}

Purpose Salinity pose severe threat to cultivation as it drastically affects the plant sustainability and yield. The intended aim of current consensus is to assess effects of sodium silicate and salicylic acid on wheat genotypes (slat tolerant and salt sensitive) grown under salt.

Methods This experiment was designed to check the effect of silicon on wheat varieties, so four different wheat genotypes named as (Umeed, Rasco, Zarghoon and Shahkaar) were grown in hydroponics under saline and normal environment. Sodium silicate and salicylic acid were applied on all varieties to determine the slat tolerance ability. Plants were harvested at maturity and different physical and chemical aspects were recorded.

Results To assess the salt stress on growth and yield of wheat genotypes. Wheat grown in saline conditions with sodium silicate supplementation showed improvement in all growth parameters as compared to the plants grown under salt stress without silicon supplementation. Higher contents of potassium were observed in plants grown under salt stress with silicon supplementation however, potassium concentration was found less in salicylic acid treatment and control under salt stress. Sodium concentration was found higher under salt stress but sodium silicate application reduced $\mathrm{Na}^{+}$uptake under salt stress. Significance increase in $\mathrm{K}^{+}: \mathrm{Na}^{+}$ratio in roots enhance the translocation which in turn elevates salt tolerance ability. Among wheat varieties potassium uptake was quite high in Umeed and Rasco as compared to Zarghoon and Shahkar.

Conclusion Based on current results it can be deduced that application of sodium silicate on different wheat varieties mitigated $\mathrm{Na}^{+}$toxicity by elevating $\mathrm{K}^{+}: \mathrm{Na}^{+}$ratio and net translocation rate in salt stressed plants.

\section{Introduction}

The earliest cultivated cereal wheat (Triticum aestivum $L$ ) is considered as staple food of Pakistan. In Pakistan wheat is cultivated on an area of 8.414 Mha with an annual production of $1.75 \mathrm{mt}$ which is quite less than its consumption[1]. Despite of all the efforts made so far; its yield is very less due to different abiotic factors mainly salinity. Salinity is a famous drought stress worldwide particularly in Pakistan 6.67 Mha of total agricultural land is affected by this. [2], [3]

Salinity exerts drastic effects on plant physiology [4]. Saline soil induces osmotic imbalance making water unavailable for plants and accumulate excessive amounts of $\mathrm{Na}^{+}$and $\mathrm{Cl}^{+}$[5]. Excessive amount of $\mathrm{Na}^{+}$and $\mathrm{Cl}^{+}$ions inhibits enzyme activity [6].

The adverse effects of salinity are improved through exogenous application of minerals. Wide variety of minerals have been used for this purpose, but $\mathrm{Si}$ is best for plant growth under various biotic and abiotic stresses [7]. It enhances the salinity tolerance in plants by maintaining the photosynthetic activity and 
ultrastructure of leaves, stimulation of ROS scavenging system and elevates water uptake and mobilization of minerals [4], [8], [9] [10].

Former literature documented that application of calcium silicate on saline stressed plant elevates chlorophyll content, transpiration, net photosynthesis and increase $\mathrm{K}^{+}$content in leaves and inhibits $\mathrm{Na}^{+}$ uptake by improving biological mechanism in cow pea and kidney beans [11].

Salicylic acid is a phenolic compound in plant, which acts as hormone like endogenous regulator. It is proposed that it also has some role in defence mechanism when plant is under biotic or abiotic stress [12].

Four wheat varieties of Balochistan i.e. Umeed, Rasco, Zarghoon and Shahkaar differing in salinity tolerance were grown in saline conditions and supplemented with sodium silicate and salicylic acid. The main purpose of this study is to understand the mechanism behind sodium silicate and salicylic acid effects on salt toxicity and its potential role in $\mathrm{K}^{+}$uptake under salt stress.

\section{Materials And Methods}

\subsection{Plant Material \& Experimental Design}

A completely randomized factorial experiment was designed using four different indigenous wheat varieties, two were salt tolerant named as: Umeed and Rasco and two were salt sensitive, pinned as Zarghoon and Shahkaar. The samples were collected from provincial and National Agricultural Research Institute in Quetta. The wheat varieties were grown in hydroponics under different treatments in laboratory of Balochistan University of Information Technology Engineering and Management Sciences [13]. In order to study more accurate behavior of wheat varieties two controls were designed C1 without salt and $\mathrm{C} 2$ with salt stress. All the varieties, treatments and controls are given in Table.1. For the authentication of this research five replicates were taken of each variety, which are further mentioned as: $R_{1}, R_{2}, R_{3}, R_{4}$ and $R_{5}$. Wheat was grown under these treatments for about 1 month in hydroponics, and some growth parameters and chlorophyll contents were recorded [10]. The leaves of harvested plants were oven dried and ground in a Willey mill, which was built in with stainless Steel Chamber containing fine powder and processed through Wet Digestion.

\section{Table.1 Treatment and varieties used in Experiment}




\begin{tabular}{|l|lll|}
\hline Varieties $(\boldsymbol{V})$ & Treatments $(\mathrm{T})$ & Control $(\mathbf{C})$ \\
\hline $\mathrm{V}_{1}=$ Umeed & $\mathrm{T}_{1}=$ sodium silicate $(1 \%)$ & $\mathrm{C}_{1}=$ without salt $(\mathrm{NaCl})$ \\
$\mathrm{V}_{2}=$ Rasco & $\mathrm{T}_{2}=$ sodium silicate + sodium chloride & $\mathrm{C}_{2}=$ with salt $(\mathrm{NaCl}=100 \mathrm{mM})$ \\
\hline $\mathrm{V}_{3}=$ Zarghoon & $\mathrm{T}_{3}=$ salicylic acid $(1 \%)$ & \\
$\mathrm{V}_{4}=$ Shahkaar & $\mathrm{T}_{4}=$ salicylic acid + sodium chloride \\
\hline 2.2 Wet Digestion for $\mathbf{N a}^{+} \mathbf{\&} \mathbf{K}^{+}$Analysis
\end{tabular}

The oven dried leaves were digested with sulphuric acid and Hydrogen peroxide according to standard wolf method (1980). Then $(0.1 \mathrm{~g})$ of dried ground material were taken in digestion tube and $2 \mathrm{ml}$ of conc $\mathrm{H}_{2} \mathrm{SO}_{4}$ was drizzled down and subjected for overnight incubation. Later, $1 \mathrm{ml}$ of $\mathrm{H}_{2} \mathrm{SO}_{4}$ (35\% A.R grade extra pure) was drizzled down and left over for few minutes. The tubes were placed inside the digestion block and heated up to $350^{\circ} \mathrm{C}$ until fumes were produced and heated for 30 minutes. Tubes were taken out from digestion block and allow to cool for few minutes and then $\mathrm{H}_{2} \mathrm{O}_{2}$ were added and heated for 20 minutes in digestion block until fumes appeared. Afterwards tubes were detached from digestion block and same step was repeated to get colorless residue. The volume of extract made up to $50 \mathrm{ml}$ for filtration and then this extract employed for $\mathrm{Na}^{+} \& \mathrm{~K}^{+}$detection by using Atomic Absorption Spectrometer (AAS), AA-7000 Shimadzu.

\section{Results}

The recent work shows that the length, fresh weight, dry weight of root and shoot as well as the chlorophyll contents of wheat are greatly affected by the salt stress when grown in saline conditions and as compared to non-saline condition. All the values were effected in all treatments (sodium silicate and salicylic acid) when compared to the control and control under salt stress (Table 2). 
Table 2

Values of growth parameters under different treatments in Non-Saline and Saline conditions

\begin{tabular}{|c|c|c|c|c|c|c|c|c|}
\hline Treatmen & & $\begin{array}{l}\text { Root } \\
\text { Length } \\
\text { (cm) }\end{array}$ & $\begin{array}{l}\text { Shoot } \\
\text { Length } \\
\text { (cm) }\end{array}$ & $\begin{array}{l}\text { Root } \\
\text { Fresh } \\
\text { Weight } \\
\text { (g) }\end{array}$ & $\begin{array}{l}\text { Root } \\
\text { Dry } \\
\text { Weight } \\
\text { (g) }\end{array}$ & $\begin{array}{l}\text { Shoot } \\
\text { Fresh } \\
\text { Weight } \\
\text { (g) }\end{array}$ & $\begin{array}{l}\text { Shoot } \\
\text { Dry } \\
\text { Weight } \\
\text { (g) }\end{array}$ & $\begin{array}{l}\text { Chlorophyll } \\
\text { Content } \\
(\mu \mathrm{g})\end{array}$ \\
\hline Control & C1 & $22.00^{b}$ & $22.50^{c}$ & $1.25^{\mathrm{C}}$ & $0.47^{b}$ & $1.75^{b}$ & $1.10^{b}$ & $1.35^{b}$ \\
\hline $\begin{array}{l}\text { Control } \\
+ \text { salt }\end{array}$ & $\mathrm{C} 2$ & $15.50^{\mathrm{e}}$ & $17.50^{\mathrm{e}}$ & $0.65^{e}$ & $0.25^{d}$ & $1.25^{\mathrm{e}}$ & $0.40^{e}$ & $0.85^{e}$ \\
\hline $\begin{array}{l}\mathrm{Na} \\
\text { Silicate }\end{array}$ & T1 & $23.50^{\mathrm{a}}$ & $27.00^{a}$ & $1.75^{\mathrm{a}}$ & $0.50^{a}$ & $1.95^{\mathrm{a}}$ & $1.20^{\mathrm{a}}$ & $1.36^{a}$ \\
\hline $\begin{array}{l}\mathrm{Na} \\
\text { Silicate } \\
+ \text { salt }\end{array}$ & T2 & $20.00^{c}$ & $\begin{array}{l}23.50 \\
b c\end{array}$ & $1.40^{b}$ & $0.35^{c}$ & $1.30^{d}$ & $0.60^{c}$ & $0.95^{d}$ \\
\hline $\begin{array}{l}\text { Salicylic } \\
\text { acid }\end{array}$ & T3 & $22.00^{b}$ & $24.00^{b}$ & $1.55^{a b}$ & $0.50^{a}$ & $1.65^{c}$ & $1.10^{b}$ & $1.32^{c}$ \\
\hline $\begin{array}{l}\text { Salicylic } \\
\text { acid + } \\
\text { salt }\end{array}$ & T4 & $17.00^{d}$ & $21.00^{d}$ & $1.15^{d}$ & $0.34^{\mathrm{cd}}$ & $1.30^{d}$ & $0.50^{d}$ & $0.91 \mathrm{de}$ \\
\hline $\begin{array}{l}\text { Means } \pm \\
\text { Std.Error }\end{array}$ & & $\begin{array}{l}20.00 \\
\pm 1.75\end{array}$ & $\begin{array}{l}22.58 \pm \\
1.59\end{array}$ & $\begin{array}{l}1.29 \pm \\
0.19\end{array}$ & $\begin{array}{l}0.40 \pm \\
0.05\end{array}$ & $\begin{array}{l}1.53 \pm \\
0.15\end{array}$ & $\begin{array}{l}0.82 \pm \\
0.18\end{array}$ & $1.12 \pm 0.12$ \\
\hline
\end{tabular}

To examine the outcomes of undertaken research all the four varieties were grown without salt (C1) and with salt (C2). Salt stress of $100 \mathrm{mM}$ of $\mathrm{NaCl}$ adversely affected the growth of wheat plants, but silicon helped to mitigate the adverse effect of salt stress. Sodium and potassium concentration in wheat plants revealed the mechanism behind this.

\subsection{Sodium}

Excess accumulation of sodium was observed in wheat cultivars grown under salt stress $\left(\mathrm{C}_{2}\right)$ as compared to $\mathrm{C}_{1}$ (without salt). The experiment was designed so that in $\mathrm{T} 1$ only Sodium Silicate $(1 \%)$ and T2 with Sodium silicate and Sodium chloride was added. It was noticed that T2 had lower concentration of sodium as compared to $\mathrm{C} 2$ that inferred that sodium silicate mitigated the salt stress in wheat plants grown under saline conditions (Fig. 1).

In second treatment of experiment T3 and T4 were opted. T4 treated with salicylic acid along with sodium chloride. In T4 lower levels of sodium ion were observed as compared to C2. It disclosed that salicylic acid in saline solution also mitigated the salt stress in wheat plants.

When varieties were examined, V1 (Umeed) in C2 accumulated more sodium ion due to sodium chloride stress. In T1 (Sodium Silicate) and $\mathrm{T}_{2}$ (Sodium silicate and salt) Umeed showed low sodium 
concentration whereas in treatments $T_{3}$ (Salicylic Acid) and $T_{4}$ (Salicylic acid and salt) minute difference was observed in $\mathrm{Na}^{+}$. Hence, Umeed showed better results with sodium silicate. Rasco $\mathrm{V}_{2}$ contained greater value of $\mathrm{Na}^{+}$ion in salt stress control $\left(\mathrm{C}_{2}\right)$. Interestingly, in variety V3 Zarghoon i.e. salt sensitive excess accumulation of $\mathrm{Na}^{+}$observed in wheat plants in both mediums (sodium silicate and salicylic acid). Shahkar $V_{4}$ salt sensitive variety showed heavy $\mathrm{Na}^{+}$accumulation in all treatments $T_{1}, T_{2}, T_{3}$ and $\mathrm{T}_{4}$ as shown in Fig. 1.

\subsection{Potassium}

The concentration of $\mathrm{K}^{+}$became very low in controlled $\mathrm{C} 2$ as compared to $\mathrm{C} 1$. In treatment $\mathrm{T}_{4}$ (salicylic acid and salt) greater amount of $\mathrm{K}^{+}$was observed compared to $\mathrm{T}_{2}$ (sodium silicate and salt).

When wheat cultivars grown in sodium silicate $\left(T_{1}\right)$ and sodium silicate with salt $\left(T_{2}\right)$ the huge deliberation of $\mathrm{K}^{+}$was detected in $\mathrm{T}_{1}$. It is inferred that surplus $\mathrm{NaCl}$ decreased the value of $\mathrm{K}^{+}$ions in wheat plants. Minute deviation in $\mathrm{K}^{+}$concentration was observed in both treatments salicylic acid $\left(\mathrm{T}_{3}\right)$ and salicylic acid with salt $\left(\mathrm{T}_{4}\right)$. It seems that salicylic acid elevates the $\mathrm{K}^{+}$concentration in both mediums but more in $\mathrm{T}_{3}$ treatment as presented in Fig. 2.

In Umeed variety $T_{2}$ depicted least $\mathrm{K}^{+}$ion concentration than $\mathrm{T}_{1}$ which deduce high uptake of Sodium Chloride adversely affected $\mathrm{K}^{+}$ion in wheat plant. In treatments $\mathrm{T}_{3}$ (salicylic Acid) and $\mathrm{T}_{4}$ (salicylic Acid + salt) slight variance was detected.

The variety Rasco has highest traces of $\mathrm{K}^{+}$ion that depicted it tolerates salt stress whereas, slight alteration in concentration was noticed in $\mathrm{T}_{3}$ and $\mathrm{T}_{4} . \mathrm{V}_{3}$ Zarghoon a salt sensitive variety detected reduction of $K^{+}$concentration than $V_{1}$ and $V_{2}$ in $T_{2}$. In $T_{3}$ and $T_{4}, V_{3}$ exhibited a less disparity in between them. $V_{4}$ Shahkaar alternative salt sensitive variety demonstrated insufficient results as compared to $V_{1}$, $V_{2}, V_{3}$ in $T_{1}$ and $T_{2}$ although little bit virtuous concentration in $T_{3}$ and $T_{4}$. Figure 2 shows the results for Potassium concentration in all the wheat cultivars.

\subsection{Potassium and Sodium ratio}

Henceforth, after several rounds of experiment we came to notion that $\mathrm{Na}^{+}$ion and $\mathrm{K}^{+}$ion have an inverse relation like in controlled and treated varieties which are $T_{1}, T_{2}, T_{3}$ and $T_{4}$, when $\mathrm{Na}^{+}$ion is high it decreases the $\mathrm{K}^{+}$ion level that best deduce the sodium toxicity in plants. In first half of experiment $\mathrm{T}_{1}$ and $\mathrm{T}_{2}$ when plant was treated with sodium steep reduction in potassium level were noticed. However drastic reduction of $\mathrm{K}^{+}$level was observed in $\mathrm{C}_{2}$. Thus, it is concluded that exogenous application of Sodium Silicate or Salicylic Acid enhance the salt tolerance in plants and help plant to sustain more $\mathrm{K}^{+}$.

\section{Discussion}


Salt stress is reduced by transpiration process, few species failed to get rid of excess salt. Consequently, it piled up and becomes enough to kill that plant cells unless they compartmentalized the salts in vacuoles thus protect the cytoplasm from ion toxicity.

Wheat genotype have poor water and salt relationship it exerts adverse effect on stomatal conductance in contrast to Barley leaves that can tolerate $500 \mathrm{mM}$ ion concentration [14]. In current research salt tolerant ability of different wheat varieties were accessed to predict which one possess salt tolerant ability. Similar study documented earlier, 50 genotypes of durum wheat was harvested after 21 days salt injury was observed due to high sodium ion concentration [5]. Previous findings proved that exogenous application of silicon exerts several beneficial effects like enhance salinity tolerance and photosynthesis, activation of antioxidant of plants, ion effect specification and many other [9], [15], [16]. Different mechanism have been proposed like reduction in salt uptake by H-ATPase, in shoots due to potassium, water enhances yield of plant by silicon application [17], [18]. Silicon is widely used to elevate water strength in plant production during longer periods of drought stress [19].

Silicon deposit into epidermis and exoderms of plants and directly affect $\mathrm{Na}^{+}$in plants [14] current consensus also proved it. $\mathrm{Si}$ constrains salinity stress in soil reduces $\mathrm{Na}^{+}$uptake by plants because excess $\mathrm{Na}^{+}$in soil restrains plant growth like in Pakistan where salinity and sodicity are core issues that convert arable land into barren land.

In Florida Sugarcane and rice were grown under silicon application to check its yield. Significance increase in yield per unit area was noticed. In turn it proofs that it enhances the chlorophyll content, yield of dry matter and amount of nitrogen in area of leaf. Similar verdict deduced in recent work on different varieties of wheat that not only upraise yield but also increases potassium ion concentration (Fig. 2).

Two field experiment were conducted by Talashilkar on two sugarcane varsities (Co-86032 and Co92013) grown on different soil named as Inceptisol and Vertisol. The intended aim of study was to analyse whether CSS (calcium silicate slag) exert any effect on plant production, mineral uptake and quality of juice. CSS beneficial impact on plant [20]. The current setting also proved that when wheat varieties were grown under salt stress increased $\mathrm{K}^{+}$: $\mathrm{Na}^{+}$ratio in plants (Fig. 3).

Silicon plays preeminent role in plant physiology, mechanical strength and thickness. To verify the impact of silicon on creeping bent (Zoysia) grass in saline medium it was grown in green house in saline medium. Si raised quality of grass by enhancing factors like rigidity, elasticity and resistance [21]. In recent work wheat varieties were grown in hypotonic conditions that deduce sodium silicate impart better effects than to salicylic acid. Consequently, Si impart profound impact in T1, T2 (with sodium silicate) than T3, T4 (salicylic acid) as potassium content was greater in T1, T2 (Fig. 3).

Former work documented that addition of silicon increase the Si content and $\mathrm{K}^{+}: \mathrm{Na}^{+}$in wheat plants than those grown deprived of Si both under control and saline conditions Inqlab-91 and Fareed-06 however when compare these varieties the better $\mathrm{K}^{+}: \mathrm{Na}^{+}$ratio and uptake of Si were observed in Inqlab-91(salt 
tolerant) in contrast to Fareed-06. In current work Umeed and Rasco profoundly increase the $\mathrm{K}^{+}$uptake than other genotypes Zarghoon and Shahkar. These two varieties Umeed and Rasco produced best results in presence of sodium silicate and salicylic acid. In previous work addition of Si also increased SOD and CAT content in non-saline and under saline conditions in Inqlab-91 and Fareed-06 at the same time improved defence activity were observed in Inqlab-91 [22]. In recent consensus the wheat genotype Rasco and Umeed produced increased potassium uptake in presence of sodium silicate as compared to salicylic acid while Zarghoon and Shahkar doesn't give profound results with sodium silicate and salicylic acid.

In arid and semiarid regions wheat were grown in the presence of silicate fertilizer, that elevates net yield [16]. Likewise, four wheat varieties Umeed, Rasco, Zarghoon, Shahkar grown in Balochistan under salt stress showed good tolerance against excessive $\mathrm{Na}^{+}$accumulation. Although tolerance level was different among wheat genotypes, Umeed and Rasco were salt resistance while Zarghoon and Shahkar were salt sensitive. Therefore, role of different silicon sources in mitigating the wheat plants grown under salt stress has been explored [23] [24]. Crop yield is hampering by saline and sodic conditions and by water imbalancing that intensify salinity in soil. High content of potassium improves water potential and sustainability of plant eventually ameliorate the $\mathrm{Na}^{+}$ion toxicity. Hence, it is concluded that exogenous application of Silicon enhances potassium uptake and mitigates $\mathrm{Na}^{+}$toxicity [18].

Salicylic acid (SA), as a hormone-like endogenous regulator, also has role in defence mechanism against biotic and abiotic stressors [12]. Application of salicylic acid had a significant effect on improving the crop growth under saline environment [25], [26]. Although results of salicylic acid in current research are in agreement for improvement of plant growth under salt stress, but the current research showed that silicon sources like sodium silicate is more effective to mitigate the salt stress when compared to salicylic acid.

Recent experiment supports the mechanism behind improvement of crops by silicon sources [23]. In saline environment application of silicon intensify potassium content while lowering sodium because $\mathrm{Si}$ enhance the membrane activity. It suggests that $\mathrm{Si}$ and $\mathrm{K}^{+}$have direct relationship that improves plant sustainability in saline and sodic condition and increase net yield.

\section{Conclusion}

Based on these findings, it can be deduced that application of silicon in wheat varieties in saline environment improved the sodium toxicity by elevating potassium content. As among four genotypes Umeed and Rasco upraised the $\mathrm{K}^{+}$uptake as compared to Zarghoon and Shahkar. Moreover, more profound results were obtained with sodium silicate s compared salicylic acid when applied under salt stress, which proves that silicon sources are more efficient to mitigate the salt stress in a better way as compared to other sources.

\section{Declarations}


Acknowledgments

Authors would like to thank especially HEC (Higher Education Commission of Pakistan) and SBK Women's University for their valued research funding. We are in immense debt to all participants of BUITEMS \& BARDC Quetta engaged in this study and support it.

\section{Authors' contributions \& consent for publication}

All authors contributed to the study conception and design. Material preparation, data collection by Nazish Sabir, Tasneem Kousar \& Sadia Sabir. The first draft of the manuscript was written by Ayesha Mushtaq and Nazish Sabir. Statistical Analysis \& Interpretation of data, and graphical representations done by Uzma Jabeen and Farrukh Bashir. All the authors commented on previous versions of the manuscript. All authors read and approved the final manuscript agreed to the sequence of authorship and for publication of this research in Silicon Journal.

\section{Availability of data and materials}

Not applicable

\section{Competing interests}

Authors declare there are no conflicts of interest.

\section{Funding}

Nil.

\section{Ethics approval}

We confirm that all authors consent to ethical standards.

\section{Informed Consent}

Not applicable

\section{References}

[1] Pakistan, G., \& Planning Commission. (2008). Pakistan Statistical Year Book.

[2] Khan, G. S. (1998). Soil salinity/sodicity status in Pakistan. Soil Survey of Pakistan, Lahore, 59.

[3] Plaut, Z., Meinzer, F. C., \& Federman, E. (2000). Leaf development, transpiration and ion uptake and distribution in sugarcane cultivars grown under salinity. Plant and Soil 218(1-2): 59-69.

[4] Hasegawa, P. M., Bressan, R. A., Zhu, J. K., \& Bohnert, H. J. (2000). Plant cellular and molecular responses to high salinity. Annual review of plant biology 51(1): 463-499. 
[5] Munns, R., James, R. A., \& Läuchli, A. (2006). Approaches to increasing the salt tolerance of wheat and other cereals. Journal of experimental botany 57(5): 1025-1043.

[6] Jaleel, C. A., Gopi, R., Manivannan, P., \& Panneerselvam, R. (2007). Responses of antioxidant defense system of Catharanthus roseus (L.) G. Don. to paclobutrazol treatment under salinity. Acta Physiologiae Plantarum 29(3): 205-209.

[7] Liang, Y. (1999). Effects of silicon on enzyme activity and sodium, potassium and calcium concentration in barley under salt stress. Plant and soil 209(2): 217.

[8] Tahir, M. A., Rahmatullah, T., Aziz, M., Ashraf, S., Kanwal, S., \& Maqsood, M. A. (2006). Beneficial effects of silicon in wheat (Triticum aestivum L.) under salinity stress. Pakistan Journal of Botany. 38(5): 1715-1722.

[9] Zhu Z., G. Wei, J. Li, Q. Qian and J. Yu. (2004). Silicon alleviates salt stress and increases antioxidant enzymes activity in leaves of salt-stressed cucumber (Cucumis sativus L.). Plant Sci., 167: 527-533.

[10] Mushtaq, A., Khan, Z., Khan, S., Rizwan, S., Jabeen, U., Bashir, F., ... \& Masood, A. (2020). Effect of Silicon on Antioxidant Enzymes of Wheat (Triticum aestivum L.) Grown under Salt Stress. Silicon 12: 2783-2788.

[11] Murillo-Amador, B., Yamada, S., Yamaguchi, T., Rueda-Puente, E., Ávila-Serrano, N., García-Hernández, J. L., ... \& Nieto-Garibay, A. (2007). Influence of calcium silicate on growth, physiological parameters and mineral nutrition in two legume species under salt stress. Journal of Agronomy and Crop Science 193(6), 413-421.

[12] Erdal, S., Aydın, M., Genisel, M., Taspınar, M. S., Dumlupinar, R., Kaya, O., \& Gorcek, Z. (2011). Effects of salicylic acid on wheat salt sensitivity. African Journal of Biotechnology 10(30): 5713-5718.

[13] Mushtaq A, Jamil N, Riaz M, Hornyak GL, Ahmed N, Ahmed SS, Shahwani MN, Malghani MNK (2017). Synthesis of silica nanoparticles and their effect on priming of wheat (Triticum aestivum L.) under salinity stress. Biological Forum 9(1):150-157

[14] Rawson, H. M., Long, M. J., \& Munns, R. (1988). Growth and development in NaCl-treated plants. I. Leaf $\mathrm{Na}+$ and $\mathrm{Cl}$-concentrations do not determine gas exchange of leaf blades in barley. Functional Plant Biology, 15(4), 519-527.

[15] Shu, L. Z., \& Liu, Y. H. (2001). Effects of silicon on growth of maize seedlings under salt stress. AgroEnvironmental Protection, 20(1), 38-40.

[16] Gong, H. J., Chen, K. M., Chen, G. C., Wang, S. M., \& Zhang, C. L. (2003). Effects of silicon on growth of wheat under drought. Journal of Plant Nutrition, 26(5), 1055-1063. 
[17] Liang, Y., Yang, C., \& Shi, H. (2001). Effects of silicon on growth and mineral composition of barley grown under toxic levels of aluminum. Journal of Plant Nutrition, 24(2), 229-243.

[18] Liang, Y., Zhang, W., Chen, Q., \& Ding, R. (2005). Effects of silicon on H+-ATPase and H+-PPase activity, fatty acid composition and fluidity of tonoplast vesicles from roots of salt-stressed barley (Hordeum vulgare L.). Environmental and Experimental Botany, 53(1), 29-37.

[19] Liang, Y., Shen, Q., Shen, Z., \& Ma, T. (1996). Effects of silicon on salinity tolerance of two barley cultivars. Journal of Plant Nutrition, 19(1), 173-183.

[20] Talashilkar, S. C., \& Savant, N. K. (1999, September). Calcium silicate slag applied to soil increased yield of rice on Inceptisol of Maharashtra state, India. In Conference Silicon in Agriculture (pp. 26-30).

[21] Linjuan, Z., Junping, J., Lijun, W., Min, L., \& Fusuo, Z. (1999). Effects of silicon on the seedling growth of creeping bentgrass and zoysiagrass. Silicon in Agriculture. LE Datnoff, GH Snyder, and GH Korndorfer, eds. Elsevier Science. Amsterdam, The Netherlands, 381.

[22] Ali, A., Haq, T. U., Mahmood, R., Jaan, M., \& Abbas, M. N. (2016). Stimulating the anti-oxidative role and wheat growth improvement through silicon under salt stress. Silicon.'

[23] Kousar, T., Sabir, N., Mushtaq, A., Rizwan, S., Jabeen, U., Bashir, F., ... \& Shahwani, M. N. (2020). Influence of Silica Gel on Ion Homeostasis in Salt Stressed Wheat Varieties of Balochistan. Silicon 1-6.

[24] Mushtaq A, Rizwan S, Jamil N, Ishtiaq T, Irfan S, Ismail T, Malghani MN, Shahwani MN (2019) Influence of silicon sources \& controlled release fertilizer on the growth of wheat cultivars of Balochistan under salt stress. Pak J Bot 51(5):1561-1567.

[25] Suhaib, M., Ahmad, I., Munir, M., Iqbal, M. B., Abuzar, M. K., \& Ali, S. (2018). Salicylic acid induced physiological and ionic efficiency in wheat under salt stress. Pakistan Journal of Agricultural Research 31(1): 79-85.

[26] Ma, X., Zheng, J., Zhang, X., Hu, Q., \& Qian, R. (2017). Salicylic acid alleviates the adverse effects of salt stress on Dianthus superbus (Caryophyllaceae) by activating photosynthesis, protecting morphological structure, and enhancing the antioxidant system. Frontiers in plant science 8: 600 .

\section{Figures}




\section{Sodium}

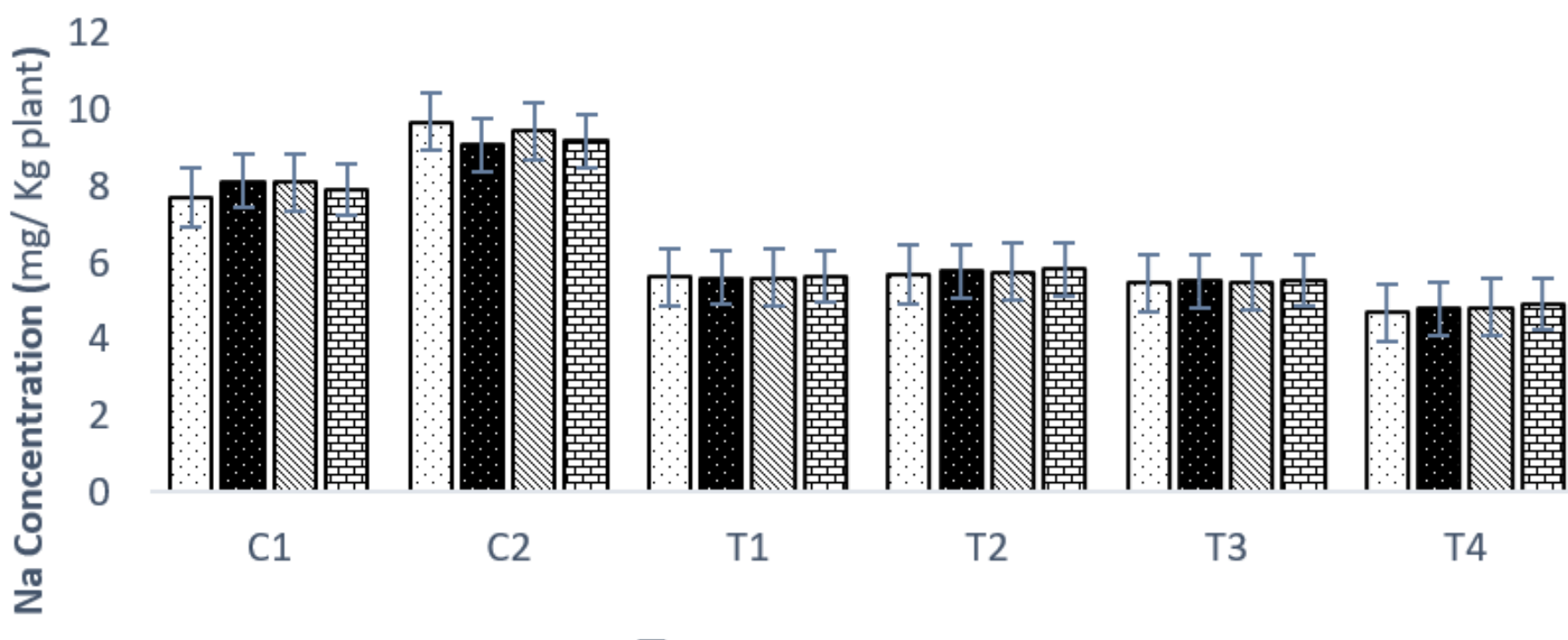

Treatments

Figure 1

Concentration of sodium in different varieties under control and treatments

Potassium

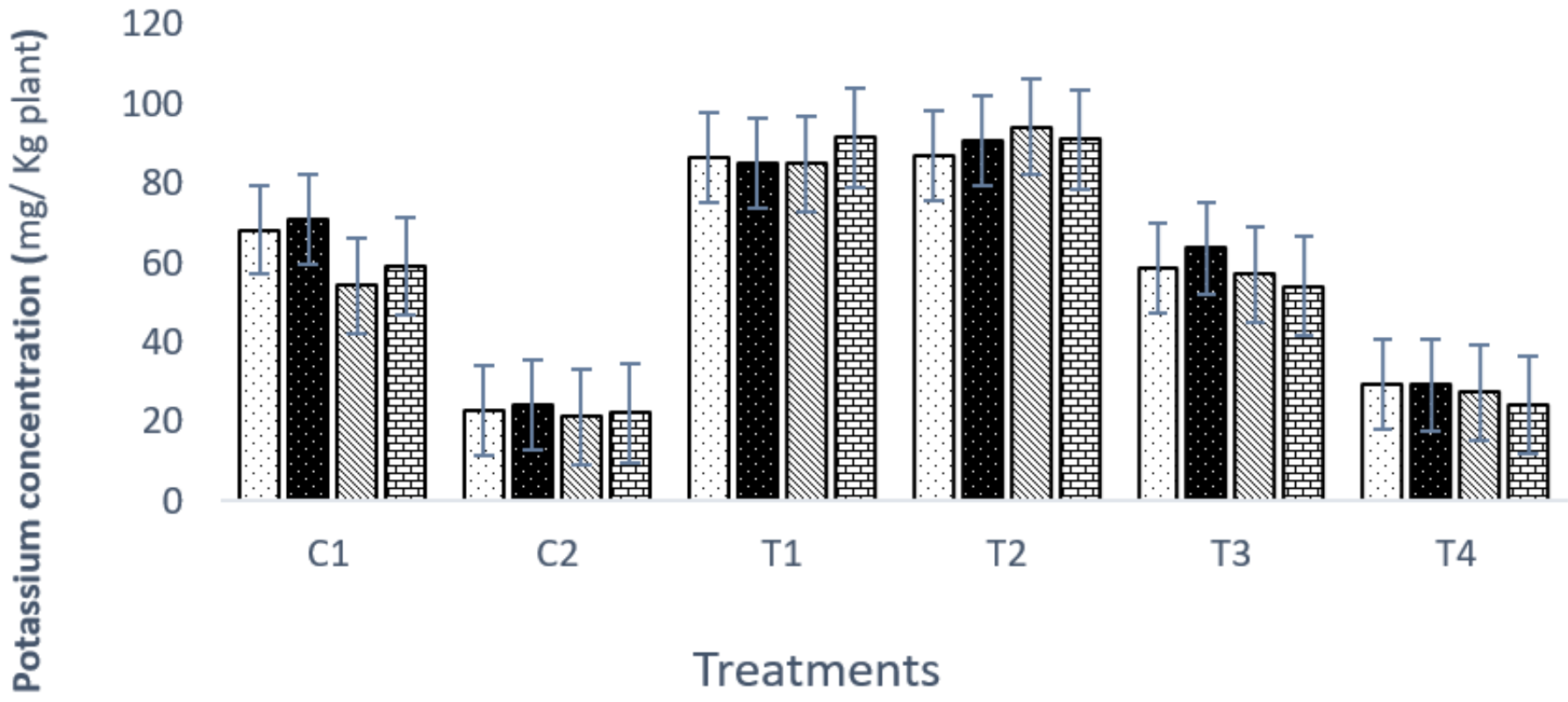

Figure 2 


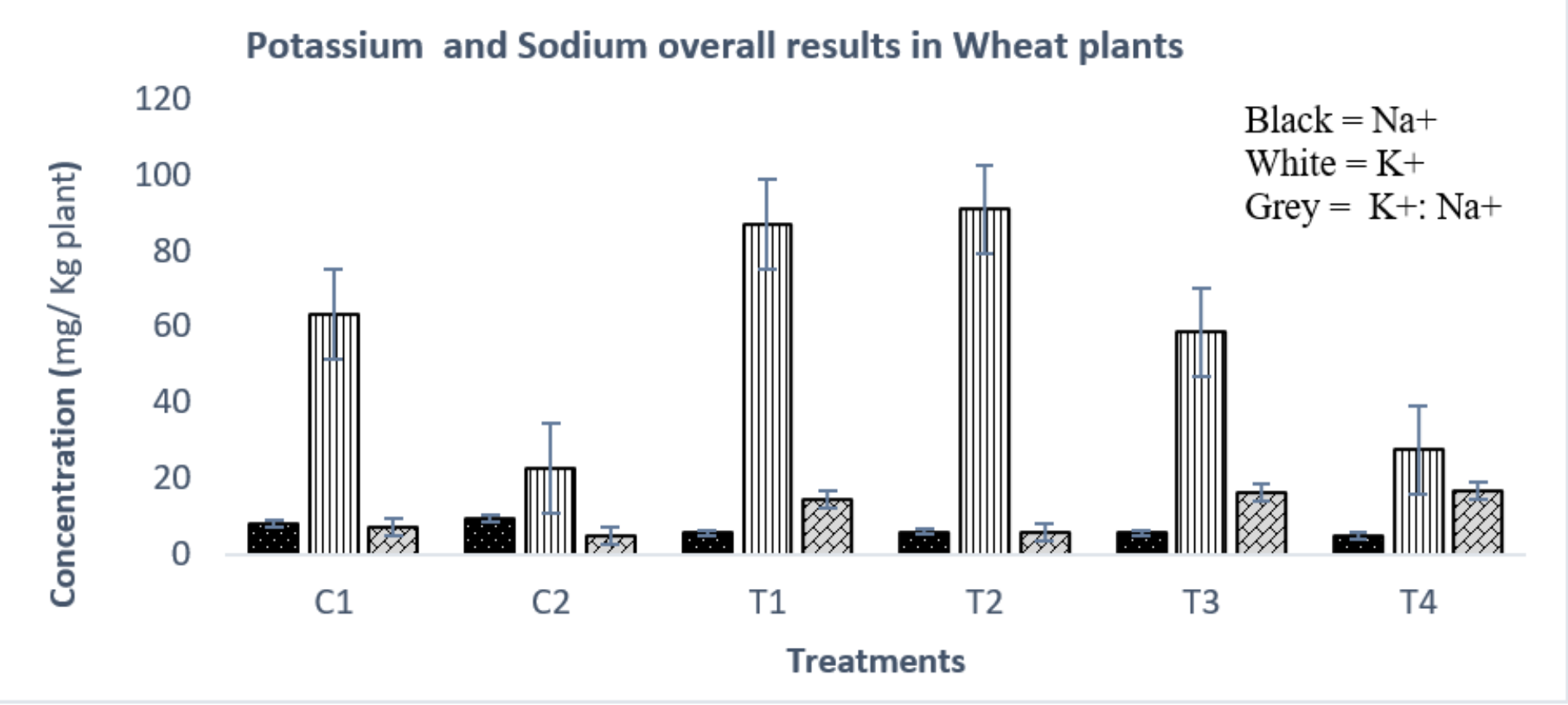

Figure 3

Potassium and sodium ratio in different varieties under control and treatments 